identifies types of verbs which remain outside the area: statals, e.g. 'know', and punctuals, e.g. 'find'. The basic problem then concerns what he calls "processives." These he analyzes more precisely, chiefly with examples from Gothic but also with reference to Greek and English, in a treatment too detailed for presentation in the space allotted here. Since, however, the analysis of verbs in a grammar is of fundamental importance, especially in computational linguistics and artificial intelligence with their heavy reliance on case theory, Lloyd's article will repay careful study by readers of this journal. His proposed longer work following the "prolegomena" may also be kept in mind.

Many other articles not mentioned here are of interest, also, for specialists in computational linguistics. Anyone teaching a course in grammar testing might, for example, ask students to program the rules in Joseph B. Voyles's "The phonology of the Old High German Tatian" (441-493). Besides testing the completeness and accuracy of his formalizations, a programmed phonology would be of no little interest in presenting forms in the scantily attested early period of German. The availability in English of an article "On some linguistic methods" (521-546) on views of Soviet scholarship by a highly regarded scholar, G.S. Sčur, illustrates a further reason for readers of this journal not to disregard this volume. One may disagree with some of Sčur's statements, for example, his "dissatisfaction with typology, whose chief aim is classification" (530); actually, typological study of syntax has provided some of the best means for insights into the development of language and for explanations, especially when one moves beyond characteristics like adjective:noun and genitive:noun, or preposition:postposition structures. Yet this and many other articles raise important questions, in a handsome tribute. In lauding a historical linguist, a highly appropriate conclusion is an article on views of a major linguist concerning the enduring problem of deep and surface structure: "Quomodo superficiei grammaticae nexus sensusque profundior in Jespersenii Syntaxi analytica dicta tractentur" (601-615) by Ladislaus Zgusta.

Winfred P. Lehmann, University of Texas at Austin

\title{
The FINITE STRING Newsletter
}

\section{Announcements}

\section{The Third Annual Conference of the Cognitive Science Society}

The Third Annual Conference of the Cognitive Science Society will be held August 19-21, 1981, on the campus of the University of California, Berkeley, in Berkeley, California. In addition to submitted papers, there will be four major addresses by speakers who are representative of important directions in Cognitive Science. There will also be four state-of-the-art symposia. These will function as tutorial sessions for particular subject areas, as well as provide a way of learning about the methodologies and concerns that the various component fields of Cognitive Science bring to bear on common problems.

Major Addresses

Robert P. Abelson, Department of Psychology Yale University

Manfred Bierwisch, Central Inst. for Linguistics

Academy of Sciences (GDR)

Thomas Kuhn, Department of Philosophy

Massachusetts Institute of Technology

William Labov, Department of Linguistics

University of Pennsy/vania
State-of-the-Art Symposia

Affect

George Mandler, Chair, UC-San Diego

Wendy Lehnert, Yale University

Katherine Lutz, Harvard University

Andrew Ortony, University of Illinois

Amos Tversky, Stanford University

Cognition and Perception

Stephen Palmer, Chair, UC-Berkeley

Geoffrey Hinton, Cambridge

Paul Kay, UC-Berkeley

Shimon Ullman, $M / T$

Mental Models of Physical Phenomena

Dedre Gentner, Chair, $B B N$

John Seely Brown, Xerox PARC

Patrick Hayes, University of Rochester

Philip Sohnson-Laird, University of Sussex

Jill Larkin, Carnegie-Mellon University

Goals

Robert Wilensky, Chair, UC-Berkeley

Richard Fikes, Xerox PARC

Barbara Hayes-Roth, RAND Corporation

James Levin, UC-San Diego

Naomi Quinn, Duke University 
For further information contact:

Nomi Feldman

Conference Coordinator

3770 Tansy

San Diego, California 92121

(714) 453-6222

\section{NWAVE X: Call for Papers}

The 1982 NWAVE Meeting will be held October 22-24, 1981, at the University of Pennsylvania in Philadelphia. Topics to be covered will include language change and variation, sociolinguistics, and discourse analysis. There will also be three special workshops on Demystifying Computational Analysis: Vowel analysis, Variable rule analysis, and Parsing. These will include demonstrations, hands-on experience, and program listings and documentation.

Abstracts must be submitted by September 15, 1981, to:

NWAVE Committee

c/o William Labov

Linguistics Laboratory

3732 Locust Walk

Philadelphia, Pennsylvania 19104

\section{COLING 82: Call for Papers}

The Ninth International Conference on Computational Linguistics will be held July 5-10, 1982, in Prague, Czechoslovakia. The Conference is sponsored by the International Committee on Computational Linguistics, in association with the Linguistic Institute of L. Star, Slovak Academy of Science, Bratislava, and the Faculty of Mathematics and Physics, Charles University, Prague. Papers are invited for presentation especially from the following domains:

- theories, methods and problems of computational linguistics

- relations of computational linguistics to computer science, mathematics, linguistics, artificial intelligence, etc.

- representation of knowledge and inferencing as they relate to language understanding

- applications of natural language processing: information retrieval, database query languages, question-answering, man-machine communication, machine translation and machine-aided translation, automatic understanding of texts, speech recognition and synthesis, etc.

Four copies of a 3-4 page, double-spaced summary must be submitted by December 1, 1981, to:

COLING 82

MFF UK, Linguistics

Malostranske n. 25

11800 Prague 1, CZECHOSLOVAKIA

\section{A Call for Papers, Panelists, and Suggestions for the 1982 NCC}

You are invited to attend and to participate in the National Computer Conference (NCC) to be held June 7-10, 1982, in the Houston Astrohall. Part of the famed Astrodomain complex, the Astrohall is touted as "America's largest one-level, air-conditioned convention facility." Its 550,000 square feet will help to fulfill the ever-increasing demand for exhibit space at the country's oldest and most prestigious computer conference.

The NCC provides a unique annual forum for computer professionals in all fields and for data processing users to share their knowledge, experience, and research developments. In addition to the technical and professional program consisting of papers, panels, surveys, and tutorials, participants will find many other important features at NCC ' 82 , including the largest exhibit of computer products and services in the world, a series of one-day professional development seminars, featured addresses and special conference activities.

You can participate by:

- volunteering to be a panelist

- proposing a technical or panel session

- writing a paper

- suggesting special activities

Deadline for submission of proposals for technical or panel sessions is September 15, 1981. Deadline for submission of papers is October 30, 1981. Authors will be notified by February 1, 1982, regarding acceptance.

Send all submissions to:

Dr. Howard L. Morgan

NCC'82 Technical Program Chairman

Department of Decision Sciences

The Wharton School/CC

University of Pennsylvania

Philadelphia, Pennsylvania 19104

\section{Eurocon ' 82 to be held in Copenhagen}

The Fifth European Conference on Electrotechnics, will take place in Copenhagen at The Technical University of Denmark, June 14-18, 1982. The Conference theme is Reliability in Electrical and Electronic Components and Systems. The conference program will be structured in such a way that it will be useful to electrical and electronic engineers, marketing experts, and other persons who are concerned with research and development, manufacturing, and applications of electrical and electronic systems. 
Further details of the Conference may be obtained from:

\author{
DIEU, Danish Enguneers' \\ Post Graduate Institute \\ The Technical University \\ of Denmark, Bldg. 208 \\ DK-2800 Lyngby, DENMARK
}

\section{Sixth European Meeting on Cybernetics and Systems Research}

The Sixth European Meeting on Cybernetics and Systems Research will be held April 12-15, 1982, at the University of Vienna, Austria, organized by the Austrian Society for Cybernetic Studies. There will be plenary lectures and symposia on General Systems Methodology, Mathematical Systems Theory, Cybernetics in Biology and Medicine, Cybernetics in Cognition and Learning, Structure and Dynamics of SocioEconomic Systems, Cybernetics in Organizational Control, Engineering Systems Methodology, Fuzzy Sets - Meeting of the EURO Working Group, Health Care Systems, Semiotic Systems, Artificial Intelligence, Systems Research on Science and Technology, and Cybernetics and Philosophy.

For a Preliminary Program and Call for Papers, contact the Chairman:

Professor Robert Trappl
Department of Medical Cybernetics
University of Vienna
Freyung $6 / 2$
A-1010 Vienna, AUSTRIA

\section{Austrian Al-Society Founded}

The Austrian Society for Artificial Intelligence (ASAI) has been founded to promote the dissemination of information on $\mathrm{AI}$, to facilitate cooperation between different AI researchers, and to support AI projects and training in Austria. Activities will include organizing lectures, workshops and conferences and issuing a (presumably) quarterly magazine.

ASAI is organizing a symposium on $\mathrm{AI}$ at the Sixth European Meeting on Cybernetics and Systems Research (EMCSR 82) in cooperation with the Austrian Society for Cybernetic Studies. (See announcement above.) The symposium will be chaired by Patrick Winston, director of the MIT AI Laboratory, and Werner Horn, president of the society. Winston will also give a plenary lecture at the meeting.

ASAI hopes to work in cooperation with people and organizations from European and non-European countries.
To get further information about the society, or to become an international affiliate, contact:

\author{
Ms. Ingeborg Steinacker \\ Vice President, ASAI \\ c/o Department of Medical Cybernetics \\ University of Vienna \\ Freyung 6 \\ A-1010 Vienna, AUSTRIA
}

\section{Al at EMCSR 82: Call for Papers}

The Austrian Society for Artificial Intelligence and the Austrian Society for Cybernetic Studies are coorganizing a symposium on Artificial Intelligence at the Sixth European Meeting on Cybernetics and Systems Research, April 13-16, 1982, in Vienna. (See announcements above.) Contributions concerning all aspects of AI will be considered. Acceptance of contributions will be determined on the basis of extended abstracts, summarizing the new material to be presented. Authors will be notified about acceptance not later than two months after receipt of the extended abstract. They will be provided with detailed instructions for the preparation of the full paper.

Three reproducible copies of extended abstracts (2-4 double-spaced pages, 600-1200 words, in English), carrying the full title of the paper, the author's name, and the author's affiliation, in that order, must be submitted by December 1, 1981, to:

Organizing Committee of the 6th EMCSR 82

Austrian Society for Cybernetic Studies

Schottengasse 3

A-1010 Vienna, AUSTRIA

\section{Special SIGART Issue on Natural Language}

A special issue of the SIGART Newsletter on Natural Language Processing is being planned for next year. The intent of the issue is to provide a survey of current research activity in Natural Language Processing and Computational Linguistics.

In February of 1977, Dave Waltz prepared a special issue of the Newsletter on this subject. People were asked to send in brief descriptions of their efforts. These notes were assembled and published, cross-referenced by topic. The result was a tremendously valuable compendium of current work in the field. Over 4 years have passed since the issue was published, so it seems appropriate to prepare an updated version at this time.

Any individual or group that would like to have their current activities included is invited to submit a brief summary of their work. Submissions should include a title, names and affiliations of people involved 
in the project, and recent or selected bibliographical references. Suggested content would be a summary of the main ideas of the effort, accomplishments, current focus, and future goals. Information about new or proposed projects is welcome, as well as information about work on languages other than English and from countries other than the United States. (Submissions must be written in English, however.)

Summaries are limited to 3 double-spaced pages, including references and examples, and should be as brief as possible, avoiding details of representations, techniques and protocols beyond short examples. Long submissions will be subject to editing. Submissions should be sent to the Guest Editor at the address below (via ARPAnet if possible) prior to November 1, 1981.

\author{
S. Jerrold Kaplan \\ Computer Science Department \\ Stanford University \\ Stanford, California 94305 \\ (415) 497-1422
}

ARPAnet address: Kaplan@SRI-AI

\section{Charles Babbage Foundation Conducts Survey}

The Charles Babbage Foundation for the History of Information Processing is conducting a nationwide survey of 14000 archival, governmental, and industrial institutions to determine if they hold records and artifacts that document the technical and socio-economic development of information processing. The survey is being conducted by mail questionnaire; each institution is invited to submit general information on archives or manuscript holdings that contain historical source materials related to information processing. Computer corporations and allied industries are requested to provide a brief overview of the types of computer-related records generated and maintained by individual companies.

The Institute's long-range plans also include publishing the results of the survey as a reference guide designed for students and scholars interested in the historical development of information processing.

CBF receives major support from AFIPS. More information about the survey may be obtained from:

Roger H. Stuewer

Charles Babbage Foundation

104 Walter Library

117 Pleasant Street, S.E.

University of Minnesota

Minneapolis, Minnesota 55455

\section{AFIPS History Speakers Directory}

The American Federation of Information Processing Societies' History of Computing Committee is preparing a Directory of speakers who are capable and willing to speak on the the history of information processing at meetings, seminars, workshops and conferences. If you would like to have your name included in the directory, contact:

\author{
Joe Ann Clifton \\ 5500 Canoga Avenue \\ Woodland Hills, California 91365
}

\section{AFIPS Presents the Harry Goode Memorial Award to C.A.R. Hoare}

At the May 5 Plenary Session of the National Computer Conference in Chicago, the American Federation of Information Processing Societies (AFIPS) announced the recipient of the 1981 Harry Goode Memorial Award. Charles Antony Richard Hoare, Professor of Computation at Oxford University, England, received this award in recognition of his pioneering work in programming languages.

AFIPS presents this award annually to honor and encourage outstanding contributions to the information processing field.

The citation reads, "In recognition of his pioneering work in the formal semantics of programming language to aid in the proof of correctness of programs, his contributions towards applying formal discipline to the program development process, and his deep insight into the process of programming language design, which has been invaluable to designers of a wide range of 'structured' programming languages."

Professor Hoare is the author of numerous papers, has been the general editor of the APIC Studies in Data Processing series (Academic Press), and is the current series editor of the Prentice-Hall International Series in Computer Science. In 1973 Professor Hoare was awarded the Association for Computing Machinery (ACM) Programming Systems and Languages $\mathrm{Pa}$ per Award, and that same year was a visiting professor at Stanford University. In 1979 he was awarded Doctor of Science Honoris Causa by the University of Southern California. He is a Distinguished Fellow of the British Computer Society and the holder of the 1980 ACM Turing Award.

C. V. Ramamoorthy is Chairman of the Harry Goode Memorial Committee; serving with him are Carl Hammer, Samir Husson, Charles Vick and Stephen Yau. 


\section{J. Ralph Leatherman Re-elected AFIPS President}

J. Ralph Leatherman, CDP, was re-elected President of AFIPS by the Board of Directors May 9 in Chicago, Illinois. The Board also re-elected Dr. Sylvia Charp Vice President and Arthur C. Lumb Secretary. Walter A. Johnson, CDP, was elected Treasurer. The officers begin their one-year terms July 1, 1981.

Mr. Leatherman is Manager of Information Services at Hughes Tool Company, Houston, Texas, where he is responsible for systems, computing and data processing, and communications. He served as Chairman of the National Computer Conference Board, Vice President of AFIPS, and Chairman of the Admissions Committee before being elected AFIPS President in 1980. He is a member of the Association for Computing Machinery (ACM) and the Data Processing Management Association (DPMA) where he has served in numerous key positions including DPMA International President.

Dr. Charp is Director of Instructional Systems of the School District of Philadelphia; she has held the office of Vice President of AFIPS for the past two terms. She also serves on AFIPS Education, Headquarters, and Washington Activities Committees and is Chairman of the National Computer Conference Board and of IFIP's Education and National Research Council--Assembly of Mathematical and Physical Sciences.

Beginning his second term as AFIPS Secretary, Mr. Lumb is Senior Distributed Processing Consultant of the Management Systems Division of Procter \& Gamble in Cincinnati, Ohio. He has served on the AFIPS Admissions and Nominating Committees and is presently a member of the Headquarters Committee. Mr. Johnson is Information Systems Director of Consolidated Papers, Inc. in Wisconsin Rapids, Wisconsin. He served as AFIPS Treasurer from June 1975-1979 and is currently Chairman of the AFIPS Finance Committee. He replaces Dr. M. Stuart Lynn who served as Treasurer for two years. Dr. Lynn is Director of Computing Affairs and Professor of Electrical Engineering and Computer Science at the University of California at Berkeley.

\section{Other Conferences}

The Seventh International Joint Conference on Artificial Intelligence will be held in Vancouver, British Columbia, Canada, August 24-28, 1981. [See AJCL $6: 3-4$, pg. 194.]

Questions about the technical program should be addressed to:

Roger C. Schank

Program Chairman, IJCAI-81

Department of Computer Science

Box 2158 Yale Station

Yale University

New Haven, Connecticut 06520

(203) 436-0606

General questions about the conference may be addressed to:

Pat Hayes

General Chairman, IJCAI-81

Department of Computer Science

Mathematical Sciences Building

University of Rochester

Rochester, New York 14627

The 1981 Annual Conference of the British Society for the Philosophy of Science will be held at Wivenhoe House at the University of Essex, September 18-20, 1981. [See $A J C L$ 6:3-4, pg. 194.] Further details of the conference may be obtained from:
Liaison Officer
University of Essex
Wivenhoe Park
Colchester CO4 3SQ, Essex, ENGLAND

The AISB School on Artificial Intelligence Skills will be held in Milton Keynes, September 21-25, 1981. [See $A J C L$ 7:1, pg. 49.] For further information, contact:

Mrs. Olwyn Wilson

AISB School Administrator

Institute of Educational Technology

Open University

Walton Hall

Milton Keynes, MK7 6AA, ENGLAND

A Symposium on Artificial and Human Intelligence, sponsored by the Human Factors Subcommittee of NATO, will be held at the Chateau de Chapeau Cornu near Lyon, France, October 26-30, 1981. [See $A J C L$ $7: 1$, pg. 49.] Further information may be obtained from the conference director:

Dr. Alick Elithorn

The Royal Free Hospital

Pond Street

London NW3 2QG, ENGLAND 
The 1981 ACM Annual Conference will be held at the Bonaventure Hotel in Los Angeles, California, November 9-11, 1981. [See $A J C L$ 6:3-4, pg. 194.] For further information contact:

Mrs. A.C. Toni Shelter

Xerox Corporation, A3-49

701 South Aviation Boulevard

El Segundo, California 90245

(213) 679-4511 $\times 1968$

The ACL is sponsoring three sessions on "Computer Modeling of Linguistic Theory" in conjunction with the Annual Meeting of the Linguistic Society of America which will be held in New York City at the Grand Hyatt Hotel, December 28-30, 1981. [See $A J C L$ 7:1, pg. 49.] For further information contact:

Stan Petrick

IBM T.J. Watson Research Center

P.O. Box 218

Yorktown Heights, New York 10598

or: Terry Langendoen

CUNY Graduate Center

33 West 42nd Street

New York, New York 10036

\section{Abstracts of Current Literature}

\section{The State-of-the-Art in Natural Language Understanding}

David L. Waltz

Coordinated Science Laboratory

University of llinois

Urbana, llinois 61801

Working Paper WP-27, Dec. 1980, 35 pages.

Research in computer understanding of natural language has led to the construction of programs which can handle a number of different types of language, including questions about the contents of data bases, stories and news articles, dialogues, and scene descriptions. This research draws on and has in turn had an affect on many other research areas, including software engineering, linguistics, psychology, philosophy, and knowledge representation. This paper provides a brief history and overview of the field, along with examples and explanations of the operation of several natural language understanding programs. The limitations of our current technology are discussed, and assessments are given of the most promising current research directions.

\section{Evaluation of Natural Language Processors}

Harry R. Tennant

Coordinated Science Laboratory

University of Illinois

Urbana, Illinois 61801

Technical Report T-103, Nov. 1980, 247 pages.

Despite a large amount of research on developing natural language understanding problems, little work has been done on evaluating their performance or potential. The evaluations that have been done have been unsystematic and incomplete. This has led to uncertainty and confusion over the accomplishments of natural language processing research.

The lack of evaluation can be primarily attributed to the difficulty of the problem. The desired behavior of natural language processors has not been clearly specified. Partial progress toward the eventual goals for natural language processors has not been delineated, much less measured.

This thesis attempts to clarify some of the difficulties behind evaluating the performance of natural language processors. It also proposes an evaluation method that is designed to be systematic and thorough. The method relies on considering a natural language processor from three viewpoints in the light of several taxonomies of issues relevant to natural language processing. Finally, an evaluation is described of PLANES, a natural language database query system.

\section{A Program Conversing In Portuguese Providing a Library Service \\ Helder Coelho \\ Centro de Informatica \\ Laboratorio Nacional de Engenharia Civil \\ 101, Av. do Brasil \\ 1799 Lisboa Codex, PORTUGAL \\ Edinburgh Ph.D. Thesis, Dec. 1979.}

TUGA is a program which converses in Portuguese to provide a library service covering the field of Artificial Intelligence. The objective of designing TUGA was the development of a feasible method for consulting and creating data bases in natural Portuguese. The resulting program allows dialogues where the program and its users behave in the way humans normally do in a dialogue setting. The program can answer, and question, in pre-defined scenarios. Users can question, answer and issue commands in a natural and convenient way, without bothering excessively with the form of the dialogues and sentences.

The original contributions of this work are: the treatment of dialogues, the adaptation of Colmerauer's natural language framework to Portuguese, the particular method for evaluating the logical structures involved in Colmerauer's framework, and the library service application itself. The program is implemented 